\title{
RISCO DE LESÃO POR PRESSÃO E FATORES ASSOCIADOS EM IDOSOS
} INTERNADOS

Luciana Julek; Universidade Estadual de Ponta Grossa; lucianajuleka@hotmail.com Clóris Regina Blanski Grden; Universidade Estadual de Ponta Grossa; reginablanski@hotmail.com

Daniele Bordin; Universidade Estadual de Ponta Grossa; daniellebordin@hotmail.com Taís Ivastcheschen; Universidade Estadual de Ponta Grossa; taisiivastcheschen@gmail.com Luciane Patrícia Andreani Cabral; Hospital Universitário Regional dos Campos Gerais; luciane.pacabral@gmail.com

\section{RESUMO}

Introdução: O processo de envelhecimento suscita modificações fisiológicas, com destaque para as alterações do sistema tegumentar, as quais podem favorecer a ocorrência de lesões de pele no idoso. Objetivo: avaliar o risco de lesão por pressão e fatores associados em idosos internados. Métodos: Pesquisa transversal, desenvolvida com 202 idosos internados nas clínicas de um hospital de ensino, selecionados por conveniência. Aplicou-se Mini Exame do Estado Mental, questionário sociodemográfico e clínico e realizada avaliação do risco de desenvolvimento de lesão por pressão, pela escala de Braden. Utilizou-se software IBM SPSS Statistics 20. Houve aprovação do Comitê de Ética em Pesquisas com seres humanos (parecer no 2.012 .327 e CAAE noo 66782217.9.0000.5689). Resultados: Predomínio de idosos classificados sem risco para o desenvolvimento de lesão por pressão $(40,6 \%)$, contudo mais da metade apresentou algum risco $(59,4$ $\%)$. A maioria era do sexo masculino (52\%), idade entre 60 e 70 anos (64,9\%), cor branca $(77,1 \%)$, casados (53\%), com baixa escolaridade $(63,4 \%)$. Verificou-se que os fatores associados ao risco de lesão por pressão foram faixa etária $(\mathrm{p}=0,001)$, multimorbidades $(\mathrm{p}=0,024)$, tempo de internação $(p=0,000)$, uso de dispositivos médicos $(p=0,000)$, dieta $(p=0,000)$ e mobilidade $(p=0,000)$. Conclusão: o estudo permitiu identificar importantes fatores associados ao risco de lesão por pressão. As ferramentas de avaliação de risco por vezes são limitadas o que afirma a necessidade de treinamento da equipe de enfermagem para seu uso, e mais do que isso, um raciocínio clínico e crítico, com olhar individualizado ao paciente idoso.

Palavras-chave: Enfermagem Geriátrica; Ferimentos e Lesões; Hospitalização. 